\title{
A New Method for Evaluating Heat Pipe Fluid Compatibility
}

\author{
Michael J. Stubblebine*, Qi Yao*, Jacob Supowit*, Ivan Catton* \\ *UCLA, 420 Westwood Plaza, Los Angeles, CA 90095, mike.stubblebine@gmail.com
}

\begin{abstract}
While heat pipes are a widely used and highly efficient means of spreading heat or transferring it from one location to another, there are some fluid-casing combinations which cannot be used due to material incompatibilities. These incompatibilities generally result in the generation of non-condensable gases such as the hydrogen gas produced when water is used with aluminum devices. Some attempts at using inhibitors in aqueous solution are found in literature but a method for screening which inhibitors to use that can also predict and assess the performance of different concentrations is not available. Using a thermodynamic approach, principles of corrosion engineering have been applied to the specific application of phase change heat transfer devices. Experimental data from previous tests has been used to show the E-pH diagrams match the reported NCG generation observed experimentally. Using thermodynamic equilibrium diagrams and measurements of heat pipe fluid $\mathrm{E}$ and $\mathrm{pH}$ can be a valuable tool when investigating passivating fluids for previously incompatible fluid-casing combinations.
\end{abstract}

Keywords: heat pipe, thermosiphon, corrosion, $N C G$, thermodynamics, passivation

\section{INTRODUCTION}

Heat pipes are a highly effective means of managing heat generated by electronics and other sources because they are able to transfer heat under near isothermal conditions across the device. Specific applications and implementations are covered extensively in existing literature [1-7]. In a heat pipe, the use of pure water in conjunction with aluminum is an incompatible combination hich will generate hydrogen gas [1]. Hydrogen is a non-condensable gas (NCG) and will build up in the condenser creating a large thermal resistance. This results in catastrophic decreases of the effective thermal performance and often leads quickly to outright failure. Ammonia heat pipes are often used in aluminum casings to avoid NCG generation, however, this has performance drawbacks and care must be taken to ensure only highly anhydrous ammonia is used. Additionally, ammonia heat pipes have a useful range of about -60 to $100^{\circ} \mathrm{C}$ while waterbased devices typically operate in a range of 30 to $200^{\circ} \mathrm{C}$ [3] and have more favorable thermophysical properties than ammonia. Therefore, the qualification of water-based fluids for use with aluminum would expand the range of operating temperatures for aluminum heat pipes.

Rassamakin et al. [8] looked at aluminum/water thermosiphons and found that a fluid $\mathrm{pH}$ of 5-6.5 and select chromate inhibitor concentrations could slow NCG generation. Novotna et al. [9, 10] also found success in investigating inhibitors to prevent NCG formation in steel based heat pipes.
Other oxidizer-containing aqueous fluids containing chromates and even permanganates have been used with aluminum thermosiphons as well [11-13] with varying success. Terdtoon et al. [14] performed an array of thermosiphon lifetime tests with the goal of studying internal tube corrosion. When disodium hydrogen phosphate was used as an inhibitor it reduced both internal tube corrosion as well as hydrogen generation in iron tubes. However, the researchers found that the aluminum tubes tested with water and any level of additives still produced hydrogen. Terdtoon et al. used tube weight before and after the testing to determine the level of corrosion accumulated over different test lengths and fit the results to an Arrhenius model.

Additional data regarding the fluid potential and $\mathrm{pH}$ before and after testing would allow for the calculation of how much oxidizers are consumed and the likely products. This would help other researchers to extrapolate the results for different sized thermosiphons and potentially heat pipes with simple wicks. The action of NCG inhibitors for heat pipes is rooted in the chemical reactions at work, therefore their consideration should be addressed in any work attempting to passivate a particular thermosiphon casing material for use with a typically incompatible fluid. E-pH, or Pourbaix diagrams, are one way to determine expected thermodynamic products of a particular metal-water system. These diagrams can also be used to judge the effect of adding inhibitors to solution. Using an aluminum thermosiphon with an aqueous fluid as an example case, a more in depth corrosion and chemical reaction analysis has been used to compliment $\mathrm{E}$ and $\mathrm{pH}$ measurements taken from past experimental compatibility tests to assess the impact of inhibitors in solution. 


\section{THERMODYNAMIC MODELING FOR HEAT PIPE PASSIVATION}

\subsection{Process Overview}

The prevention of hydrogen gas generation using inhibitors in aluminum heat pipes can be investigated by modeling the thermodynamic stability of a multi-component, aqueous solution. Initial screening using thermodynamics can limit the number of chemicals and range of concentrations tested in aqueous solutions tested for compatibility within a sealed phase change heat transfer device such as a heat pipe or thermosiphon. E-pH diagrams are used to predict the most thermodynamically stable species at a given fluid $\mathrm{pH}$ and potential when equilibrium has been reached. Both $\mathrm{pH}$ and potential are dependent upon the specific chemicals and their concentrations existing in solution as well as temperature. An example of an E-pH diagram can be found for a simple water system in Figure 1.

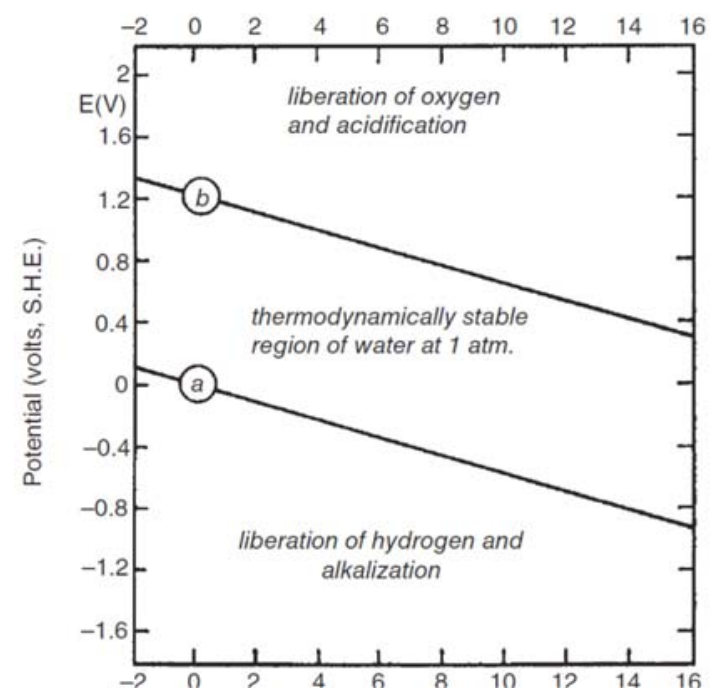

Figure 1: E-pH diagram for $\mathrm{H}_{2} \mathrm{O}$ at $25^{\circ} \mathrm{C}$ [15]

A highly reducing solution will exist below the bottom diagonal line in Figure 1 where hydrogen gas will be liberated from ionization of water itself. Hydrogen gas can also be generated via chemical reactions with a metal electrode. This hydrogen evolution can be prevented or diminished substantially by establishing a protective oxide barrier on the metal surface. The favorability of an oxide layer can also be determined via thermodynamics, however, more data may be required to evaluate the protectiveness of that oxide. Figure 2 shows an E$\mathrm{pH}$ diagram which considers such a metal-water equilibrium.

Solutions containing strong oxidizers can move the system equilibrium to more oxidizing conditions where both water and a protective oxide coating are thermodynamically stable and gas generation rates are substantially lowered. By overlaying the E$\mathrm{pH}$ diagrams of multiple metal-water systems one can get an idea of the stability of each constituent with respect to the E-pH conditions created by the concentration of each in solution.

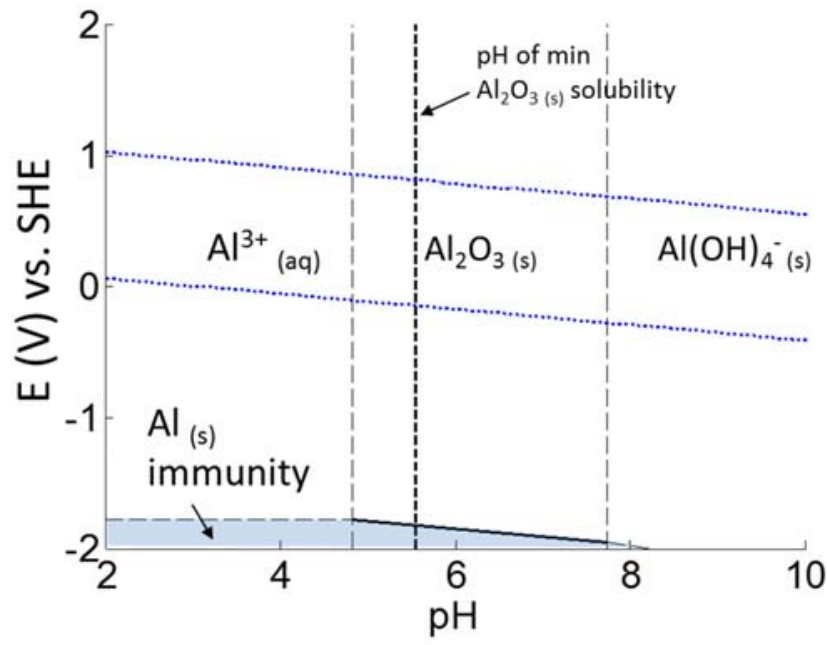

Figure 2: E-pH diagram for $\mathrm{Al}-\mathrm{H}_{2} \mathrm{O}$ system at $25^{\circ} \mathrm{C}$

A Matlab code has been written to generate E-pH diagrams, such as Figure 2, as a function of temperature for select species. Figure 3 shows such a diagram containing information on the stability of chromium, aluminum, and manganese in an aqueous environment. Labels for each region have been left off of this figure to keep the information contained within it manageable, but it should be noted that each enclosed region represents the most thermodynamically stable form of the metal in an aqueous solution. By measuring the $\mathrm{E}$ and $\mathrm{pH}$ of a system, one can plot the point on the diagram and determine the thermodynamically favored species for each elemental component.

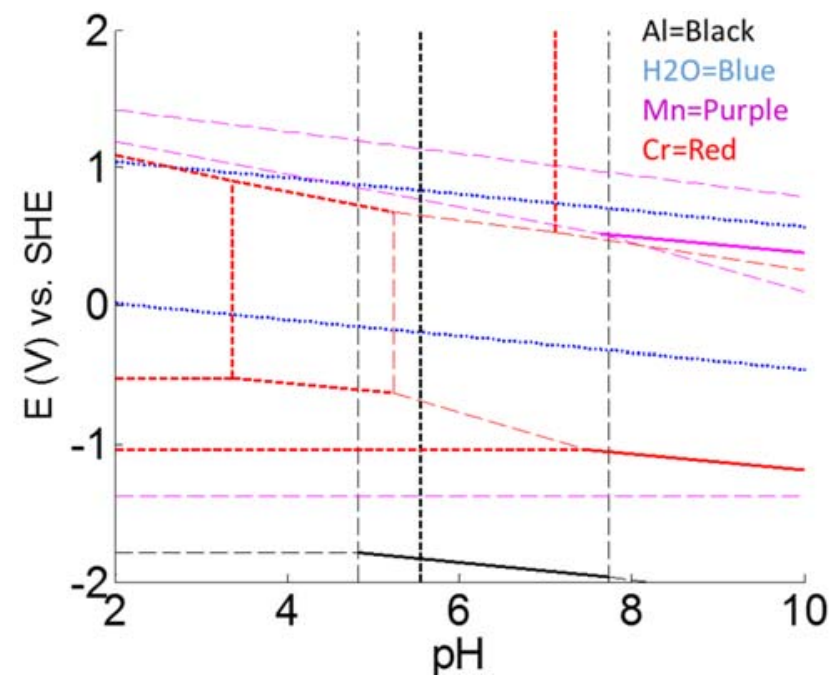

Figure 3: E-pH diagram for $\mathrm{Al}-\mathrm{Cr}-\mathrm{Mn}-\mathrm{H}_{2} \mathrm{O}$ system at $25^{\circ} \mathrm{C}$

Typically, the resulting reactions from metals in aqueous solution will release either oxygen or hydrogen gas. For metals with a large immunity region encompassing standard pure water conditions, such as copper, this rate is extremely low and often neglected. However, it is important to note that there is no situation in which a metal electrode in aqueous solution will not liberate either oxygen or hydrogen gas. This applies to copper electrodes as well even though it is commonly considered to be "NCG free" when used with water. In copper phase change heat transfer (PCHT) devices, the corrosion and NCG generation rates are so small under most operating conditions that we often refer to it in practice as an inert combination. 
E-pH diagrams correspond to thermodynamic equilibrium possibilities at a particular temperature of the system. Theoretical passivation environments can be determined for a variety of thermal conditions. A benefit of this approach to find oxidizing inhibitors that have stable oxides at an $\mathrm{E}, \mathrm{pH}$ region which overlaps with aluminum oxide. The remaining challenge is to design a fluid which can maintain the closed system within these ranges via chemical reactions inside the PCHT device. Sealed devices under partial vacuum, such as a heat pipe, present a particular problem since even trace quantities of NCG can represent a thermal barrier under low pressure. These challenges can be better addressed with a thermodynamic basis for selecting inhibitors and their concentrations as well as evaluating relative success by measuring fluid properties before and after testing. A Matlab program capable of generating E-pH stability diagrams for any given temperature was built for this purpose.

\subsection{Temperature Dependent E-pH Diagrams}

For electrochemical reactions involving the transferrance of electrons, Pourbaix diagram lines are drawn from the Nernst equation,

$$
E(T)=E^{\circ}(T)-2.303 \frac{R T}{n F} \log Q
$$

Where the standard reduction potential is written as,

$E^{\circ}(T)=-\frac{\Delta G_{r}^{\circ}(T)}{n F}$

Purely chemical reactions are evaluated using the Van't Hoff equation,

$\Delta G_{r}^{\circ}=-2.303 \log K$

Note that equation (1) uses $\mathrm{Q}$, the reaction quotient, while equation (3) makes use of $\mathrm{K}$, the equilibrium constant. At equilibrium conditions, such as those necessary for E-pH stability diagrams, the two are equivalent $(\mathrm{Q}=\mathrm{K})$ and there is no discrepancy. The "not" or "o" superscript on some variables indicates it is referenced to standard conditions of $1 \mathrm{~atm}$ pressure and 1 molar solution concentration. The definition of $\mathrm{K}$ is,

$K=\frac{[C]^{c}[D]^{d}}{[A]^{a}[B]^{b}}$

Where the lowercase letters are species coefficients in the representative chemical reaction in equation (5). The capital letters are the species themselves. Bracketed capital letters in equation (4) represent the individual species molar concentration or activity, which, at dilute concentrations that will be used in this work are essentially equivalent.

$a A+b B=c C+d D$

The fluid $\mathrm{pH}$ enters the equation through the concentration, or activity, of the aqueous hydrogen ion through the following definition for $\mathrm{pH}$,

$$
p H=-\log \left[H_{(\mathrm{aq})}^{+}\right]
$$

When drawing lines for the equilibrium diagrams, all other aqueous ion species concentrations are known in that we assume a small value below which that species' existence is defined as negligible. In adherence with standard convention, these ion concentrations in solution are assumed to be equal to $10^{-6} \mathrm{M}$ and pure liquids, such as water, and solids are assumed to be equal to 1 .

For both chemical and electrochemical situations, the standard Gibbs free energy change of reaction, $\Delta G_{r}^{\circ}$, can be found in most thermodynamic tables at $25^{\circ} \mathrm{C}$. E-pH diagrams based on this temperature are also readily available for a multitude of systems. However, if one wants to construct diagrams at any given temperature $\Delta G_{r}^{\circ}(T)$, the standard Gibbs free energy as a function of temperature, must be found. This requires more calculation steps and data is less readily available in a convenient form, particularly for aqueous, ionic species.

Starting with the definition of Gibbs free energy, enthalpy, and the changes in each we have,

$G=H-T S$

$d G=d H-T d S-S d T$

$H=U+P V$

$d H=d U+P d V+V d P$

By plugging the change of enthalpy into the equation for Gibbs free energy and cancelling terms we get the following,

$d G=V d P-S d T$

Where relations for volume, $\mathrm{V}$, and entropy, $\mathrm{S}$, are obtained by recognizing that, as a state function, Gibbs free energy in equation (11) can be represented in the following way,

$$
\begin{aligned}
& d G=\left(\frac{\partial G}{\partial P}\right)_{T} d P+\left(\frac{\partial G}{\partial T}\right)_{P} d T \\
& \left(\frac{\partial G}{\partial P}\right)_{T}=V \\
& \left(\frac{\partial G}{\partial T}\right)_{P}=-S
\end{aligned}
$$

Similarly, the Gibbs free energy at any given temperature and pressure, $G(T, P)$, can be assumed to be a composite sum of $G\left(T, P_{r}\right)$, the Gibbs energy at any temperature and a reference pressure of $1 \mathrm{~atm}$, and the second term in equation (15). This second term represents the change in Gibbs energy from the reference pressure to any given pressure while temperature is held constant.

$G(T, P)=G\left(T, P_{r e f}\right)+\int_{P_{r e f}}^{P}\left(\frac{\partial G}{\partial P}\right)_{T} d P$

The first term to the right of the equality in equation (15) is obtained from the definition of Gibbs free energy as follows in equation (16).

$G\left(T, P_{r e f}\right)=H\left(T, P_{r e f}\right)-T S\left(T, P_{r e f}\right)$ 
Plugging this term back into equation (15) and removing the partial differential for $\mathrm{G}$ in the pressure term by plugging $\mathrm{V}$ back in we get equation (17).

$G(T, P)=H\left(T, P_{r e f}\right)-T S\left(T, P_{r e f}\right)+\int_{P_{r e f}}^{P} V d P$

The $\int_{P_{r e f}}^{P} V d P$ term can be assumed negligible. Uhlig's corrosion handbook [16] suggests this term is negligible for $\mathrm{P}<$ 100 atm, giving,

$G\left(T, P_{r e f}\right)=H\left(T, P_{r e f}\right)-T S\left(T, P_{r e f}\right)$

Our equation now looks similar to the original definition of Gibbs energy, however, we have eliminated the pressure dependence and learned that the temperature dependence is stronger and can be decoupled from the pressure. Furthermore, we have rewritten our equation for Gibbs free energy such that it is referenced to standard pressure at $P_{\text {ref }}=1 \mathrm{~atm}$.

Applying the well-known relationships for temperature dependent enthalpy and entropy in equations (19) and (20),

$$
\begin{aligned}
& H\left(T, P_{r e f}\right)=H\left(T_{r e f}, P_{r e f}\right)+\int_{T_{r e f}}^{T} C_{p}(T) d T \\
& S\left(T, P_{r e f}\right)=S\left(T_{r e f}, P_{r e f}\right)+\int_{T_{r e f}}^{T} \frac{C_{p}(T)}{T} d T
\end{aligned}
$$

Where the first term right of the equality in each are equivalent to standard enthalpy of formation and absolute standard entropy as seen in equations (21) and (22).

$H\left(T_{r e f}, P_{r e f}\right)=\Delta H_{f}^{\circ}$

$S\left(T_{r e f}, P_{r e f}\right)=S^{\circ}$

After plugging back into equation (18) the final equation comes out to be,

$$
\begin{aligned}
G^{\circ}(T) & =\Delta H_{f}^{\circ}\left(T_{r e f}\right) \\
& +\int_{T_{r e f}}^{T} C_{p}^{\circ}(T) d T \\
& -T\left[S^{\circ}\left(T_{r e f}\right)+\int_{T_{r e f}}^{T} \frac{C_{p}^{\circ}(T)}{T} d T\right]
\end{aligned}
$$

This is a pseudo "absolute" Gibbs energy in that it is used as an intermediate step in the following equation (24). True Gibbs energies cannot be absolute in nature.

$$
\Delta G_{r}^{\circ}(T)=\sum_{\text {products }}\left[G^{\circ}(T)\right]-\sum_{\text {reactants }}\left[G^{\circ}(T)\right]
$$

The result in equation (23) is calculated for each species in a given chemical or electrochemical reaction and plugged into equation (24) to determine the Gibbs free energy of that particular reaction. It is this value that is used in the Nernst or Van't Hoff equations to determine E-pH relationships which can be plotted on a Pourbaix diagram.

\subsection{High Temperature Thermodynamic Properties}

The thermodynamic properties of aqueous ionic species are not as readily available in the literature as many solid or liquid materials. The Helgeson-Kirkham-Flowers method for determining high temperature thermodynamic properties as a function of temperature was used when experimental correlations were unavailable. This method was first published by Helgeson and Kirkham [17] and has since been updated and revised as newer experimental data becomes available [18-20].

The basic equation given by Shock and Helgeson [19] for standard partial molal specific heat is,

$$
\begin{aligned}
C_{p}^{\circ}(T)= & c_{1}+\frac{c_{2}}{(\mathrm{~T}-\theta)^{2}} \\
& -\left(\frac{2 T}{(T-\theta)^{3}}\right)\left[a_{3}\left(P-P_{r e f}\right)+a_{4} \ln \left(\frac{\psi+P}{\psi+P_{r e f}}\right)\right] \\
& +\omega T X+2 T Y\left(\frac{\partial \omega}{\partial T}\right)_{P}-T\left(\frac{1}{\varepsilon}-1\right)\left(\frac{\partial^{2} \omega}{\partial T^{2}}\right)_{P}
\end{aligned}
$$

Where $c_{1}, c_{2}, a_{3}$, and $a_{4}$ are all species-specific constants which are independent of both temperature and pressure, $\mathrm{T}$ is temperature, and $\mathrm{P}$ is pressure. The variable $\omega$ is a temperature and pressure dependent Born coefficient. There are two global constants in this equation, $\Theta=228 \mathrm{~K}$ and $\psi=2600$ bars. This specific heat equation gives the value for standard state, taken as 1 molal solutions, and is valid for variable temperature and pressure. The variable $\mathrm{X}$ is the Born parameter and is a function of $\varepsilon$, the temperature dependent dielectric constant of water, data for which is taken from Shock et al. [21]. Similarly, Y is also a function only of the temperature dependency of water's dielectric constant.

$X=\frac{1}{\varepsilon}\left[\left(\frac{\partial^{2} \ln \varepsilon}{d T^{2}}\right)_{P}-\left(\frac{\partial \ln \varepsilon}{d T}\right)_{P}^{2}\right]$

Using the previous assumption that the pressure dependency of aqueous species properties is negligible, this equation can be simplified and the terms containing $\mathrm{a}_{3}$ and $\mathrm{a}_{4}$ can be neglected. Additionally, Shock and Helgeson [19] report that $\omega$ can be taken as a constant for temperatures below $170^{\circ} \mathrm{C}$ and for pressures near the vapor-liquid saturation curve of water. This allows all partial derivative terms involving $\omega$ to be neglected. The result is,

$C_{p}^{\circ}(T)=c_{1}+\frac{c_{2}}{(\mathrm{~T}-\theta)^{2}}+\omega T X$

Where $\mathrm{X}$ is given previously in equation (26) and the remaining constants for most species relevent to this work are tabulated in Shock et al. [21].

\section{APPLICATION TO ALUMINUM HEAT PIPES WITH WATER BASED FLUIDS}

\subsection{E-pH Diagram of Aluminum/Water System}

The first step in the creation of E-pH diagrams is to identify the chemical and electrochemical equations which will be considered for the application. There may be a large number of reactions which can happen, however, the relevant equations will likely not include all of these. For the aluminum/water system, the following reactions (28), (29), (30), (31), and (32) are the ones selected for this study. 
$A l_{(a q)}^{3+}+3 e^{-} \rightarrow A l_{(s)}$

$\mathrm{Al}_{2} \mathrm{O}_{3(s)}+6 \mathrm{H}_{(a q)}^{+}+6 e^{-} \rightarrow 2 \mathrm{Al}_{(s)}+3 \mathrm{H}_{2} \mathrm{O}_{(l)}$

$\mathrm{Al}(\mathrm{OH})_{4(a q)}^{-}+4 \mathrm{H}_{(a q)}^{+}+3 e^{-} \rightarrow A l_{(s)}+4 \mathrm{H}_{2} \mathrm{O}_{(l)}$

$\mathrm{Al}_{2} \mathrm{O}_{3(s)}+6 \mathrm{H}_{(a q)}^{+} \rightarrow 2 \mathrm{Al}_{(a q)}^{3+}+3 \mathrm{H}_{2} \mathrm{O}_{(l)}$

$2 \mathrm{Al}(\mathrm{OH})_{4(a q)}^{-}+2 \mathrm{H}_{(a q)}^{+} \rightarrow \mathrm{Al}_{2} \mathrm{O}_{3(s)}+5 \mathrm{H}_{2} \mathrm{O}_{(l)}$

The above equation set is a subset of all chemical equilibria which are theoretically possible. Considering all species possible is not only impractical but also unrealistic. A number of factors were considered when the species and chemical equations were selected. Aluminum is amphoteric meaning that its oxides prefer neutral $\mathrm{pH}$ conditions. Therefore, aluminum oxide will dissolve into solution at both high and low $\mathrm{pH}$ numbers and exist as ionic species (i.e. corrosion). At high $\mathrm{pH}$ aluminum oxide will dissolve into $\mathrm{Al}(\mathrm{OH})^{-}{ }_{4}$ and at low $\mathrm{pH}$ into $\mathrm{Al}^{3+}$.

Corrosion of aluminum at high and low $\mathrm{pH}$ levels are both unwanted for heat pipe applications as they will both evolve hydrogen gas.

$2 A l_{(\mathrm{s})}+6 H_{(a q)}^{+} \rightarrow A l_{(\mathrm{aq})}^{3+}+3 H_{2(\mathrm{~g})}$

$2 \mathrm{Al}_{(\mathrm{s})}+6 \mathrm{H}_{2} \mathrm{O}_{(\mathrm{l})}+2 \mathrm{OH}_{(a q)}^{-} \rightarrow 2 \mathrm{Al}(\mathrm{OH})_{4(\mathrm{aq})}^{-}+3 \mathrm{H}_{2(\mathrm{~g})}$

Equation (33) represents the equation for aluminum in acidic media while equation (34) represents an alkaline medium. The neutral $\mathrm{pH}$ range of 4-9 can be considered a starting region within which aluminum oxides are most stable for a wide temperature range $[16,22]$. Diagrams will therefore be constructed for the $\mathrm{pH}$ range just outside of this for $\mathrm{pH} 2-10$ and species which exist primarily outside this region can be neglected. The species considered for aluminum were selected to be consistent with those used in Ghali [22].

The following water reactions (35) and (36) must also be considered to discover information about the stability of water itself and if hydrogen gas or oxygen gas might be potentially released.

$$
\begin{aligned}
& \frac{1}{2} O_{2(g)}+2 H_{(a q)}^{+}+2 e^{-} \rightarrow H_{2} O_{(l)} \\
& 2 H_{(a q)}^{+}+2 e^{-} \rightarrow H_{2(g)}
\end{aligned}
$$

Figure 4 shows the temperature dependent results of a Matlab code which computes the Gibbs free energy as a function of temperature for each species and then each reaction above in equations (28) through (36). By convention, short, dashed, blue lines represent the equilibria of water, long, black, dashed lines represent equilibrium between an ionic species and a solid species, while solid lines represent equilibrium between two solid species.

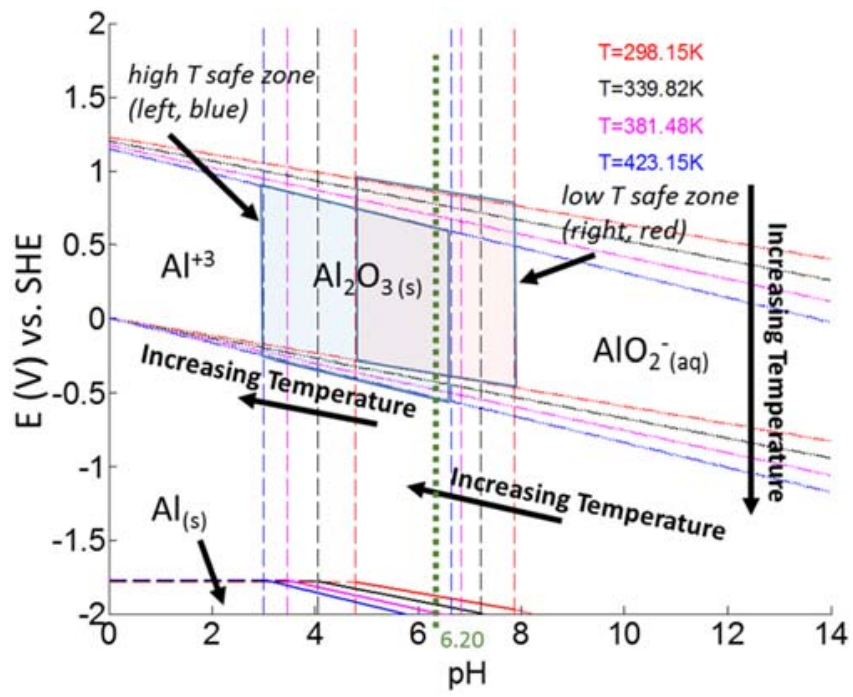

Figure 4: E-pH diagram for $\mathrm{Al}-\mathrm{H}_{2} \mathrm{O}$ diagram showing equilibria trends with increasing temperature

The vertical, dotted, green line in Figure 4 represents a reference $\mathrm{pH}$ of 6.20 which fits within the stability region for aluminum oxide at both high and low temperatures. The temperature dependency of the diagrams allows for the selection of inhibitors and $\mathrm{pH}$ level which remain within the desired stable regions throughout the anticipated temperature range the device will see in its lifetime.

Initial $\mathrm{pH}$ and $\mathrm{E}$ of a designed fluid can be picked and then measured experimentally. Next, calculations can be performed which determine the expected $\mathrm{pH}$ and $\mathrm{E}$ as the inhibitors are consumed. An important consideration to remember is that the geometry of a heat pipe or thermosiphon is itself representative of the amount of casing material available for reaction. Therefore, the same fluid with same initial $\mathrm{E}$ and $\mathrm{pH}$ might have different measurements after testing since there are different amounts of available aluminum (potentially the limiting reagent) in each situation. Both before and after points should be plotted on a diagram to visually see the effect of using a solution with a given amount of inhibitors in different devices with different surface areas. Additional tests and data should be gathered about the expected protectiveness of the oxides created. Post-test measurements of E, $\mathrm{pH}$ can help determine if the barrier oxide was protective or not. If the oxide is porous and allows significant reactions with the base metal this can be reflected by these measurements.

\subsection{Addition of Inhibitors}

By overlaying E-pH diagrams for different metal/water systems, one can determine regions where another chemical, such as a strong oxidizer, can make an oxide coating stable where it would otherwise not be. For this reason, E-pH diagrams were constructed in the same manner as was done for aluminum for both the manganese and chromium metal-water systems. These inhibitors were selected based on those used in past literature $[8-10,12,13,23]$. Chromium and its oxides are also well known for their protective oxides for aluminum and mild steels. Chemical and electrochemical equations selected for the these systems are shown in the following equations, followed by their respective diagrams at $25^{\circ} \mathrm{C}$. 
3.2.1 Manganese

$M n_{(a q)}^{2+}+2 e^{-} \rightarrow M n_{(s)}$

$\mathrm{MnO}_{2(s)}+4 \mathrm{H}_{(a q)}^{+}+2 e^{-} \rightarrow \mathrm{Mn}_{(a q)}^{2+}+\mathrm{H}_{2} \mathrm{O}_{(l)}$

$\mathrm{Mn}_{2} \mathrm{O}_{3(s)}+6 \mathrm{H}_{(a q)}^{+}+e^{-} \rightarrow 2 \mathrm{Mn}_{(a q)}^{2+}+3 \mathrm{H}_{2} \mathrm{O}_{(l)}$

$\mathrm{MnO}_{4(a q)}^{-}+4 \mathrm{H}_{(a q)}^{+}+3 e^{-} \rightarrow \mathrm{MnO}_{2(s)}+2 \mathrm{H}_{2} \mathrm{O}_{(l)}$

$2 \mathrm{MnO}_{2(s)}+\mathrm{H}_{2} \mathrm{O}_{(l)}+2 e^{-} \rightarrow \mathrm{Mn}_{2} \mathrm{O}_{3(s)}+2 \mathrm{OH}_{(a q)}^{-}$

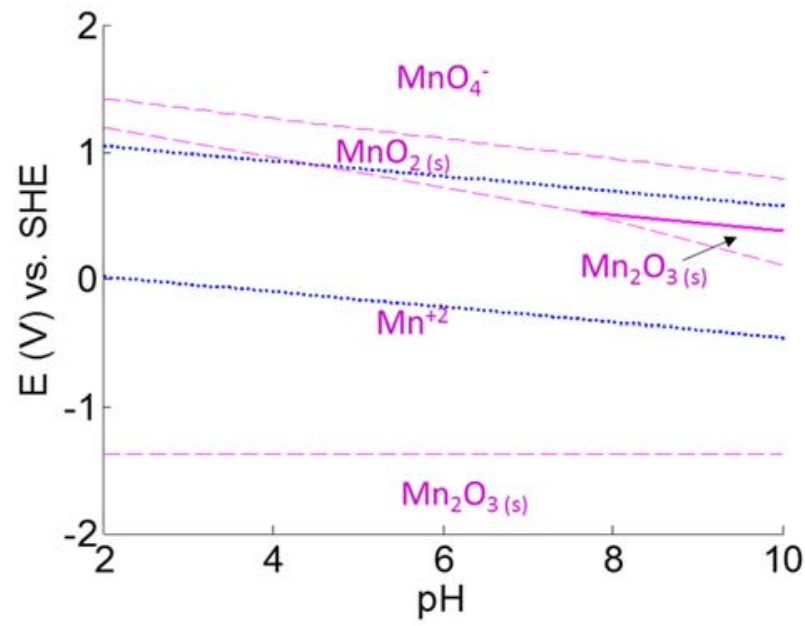

Figure 5: E-pH diagram for $\mathrm{Mn}-\mathrm{H}_{2} \mathrm{O}$ at $25^{\circ} \mathrm{C}$

\subsubsection{Chromium}

$C r_{(a q)}^{3+}+e^{-} \rightarrow C r_{(a q)}^{2+}$

$\mathrm{HCrO}_{4(a q)}^{-}+7 \mathrm{H}_{(a q)}^{+}+3 e^{-} \rightarrow \mathrm{Cr}_{(a q)}^{3+}+4 \mathrm{H}_{2} \mathrm{O}_{(\mathrm{l})}$

$C r_{(a q)}^{2+}+2 e^{-} \rightarrow C r_{(\mathrm{s})}$

$2 \mathrm{CrO}_{4(a q)}^{2-}+10 \mathrm{H}_{(a q)}^{+}+6 e^{-} \rightarrow \mathrm{Cr}_{2} \mathrm{O}_{3(\mathrm{~s})}^{3+}+5 \mathrm{H}_{2} \mathrm{O}_{(\mathrm{l})}$

$\mathrm{Cr}_{2} \mathrm{O}_{3(\mathrm{~s})}+6 \mathrm{H}_{(a q)}^{+}+6 e^{-} \rightarrow 2 \mathrm{Cr}_{(\mathrm{s})}+3 \mathrm{H}_{2} \mathrm{O}_{(\mathrm{l})}$

$\mathrm{Cr}_{2} \mathrm{O}_{3(\mathrm{~s})}+6 \mathrm{H}_{(a q)}^{+}+2 e^{-} \rightarrow 2 \mathrm{Cr}_{(\mathrm{aq})}^{2+}+3 \mathrm{H}_{2} \mathrm{O}_{(\mathrm{l})}$

$\mathrm{HCrO}_{4(a q)}^{-}+6 \mathrm{H}_{(a q)}^{+}+3 e^{-} \rightarrow \mathrm{Cr}(\mathrm{OH})_{(a q)}^{2+}+3 \mathrm{H}_{2} \mathrm{O}_{(\mathrm{l})}$

$\mathrm{Cr}_{2} \mathrm{O}_{3(\mathrm{~s})}+4 \mathrm{H}_{(a q)}^{+} \rightarrow 2 \mathrm{Cr}(\mathrm{OH})_{(\mathrm{aq})}^{2+}+\mathrm{H}_{2} \mathrm{O}_{(\mathrm{l})}$

$\mathrm{HCrO}_{4(\mathrm{aq})}^{-} \rightarrow \mathrm{CrO}_{4(\mathrm{aq})}^{2-}+\mathrm{H}_{(a q)}^{+}$

$\mathrm{Cr}(\mathrm{OH})_{(a q)}^{2+}+\mathrm{H}_{(a q)}^{+}+e^{-} \rightarrow \mathrm{Cr}_{(a q)}^{2+}+\mathrm{H}_{2} \mathrm{O}_{(\mathrm{l})}$

$\mathrm{Cr}_{(a q)}^{3+}+\mathrm{H}_{2} \mathrm{O}_{(\mathrm{l})} \rightarrow \mathrm{Cr}(\mathrm{OH})_{(a q)}^{2+}+H_{(a q)}^{+}$

$2 \mathrm{HCrO}_{4(a q)}^{-}+8 \mathrm{H}_{(a q)}^{+}+6 e^{-} \rightarrow \mathrm{Cr}_{2} \mathrm{O}_{3(\mathrm{~s})}+5 \mathrm{H}_{2} \mathrm{O}_{(\mathrm{l})}$

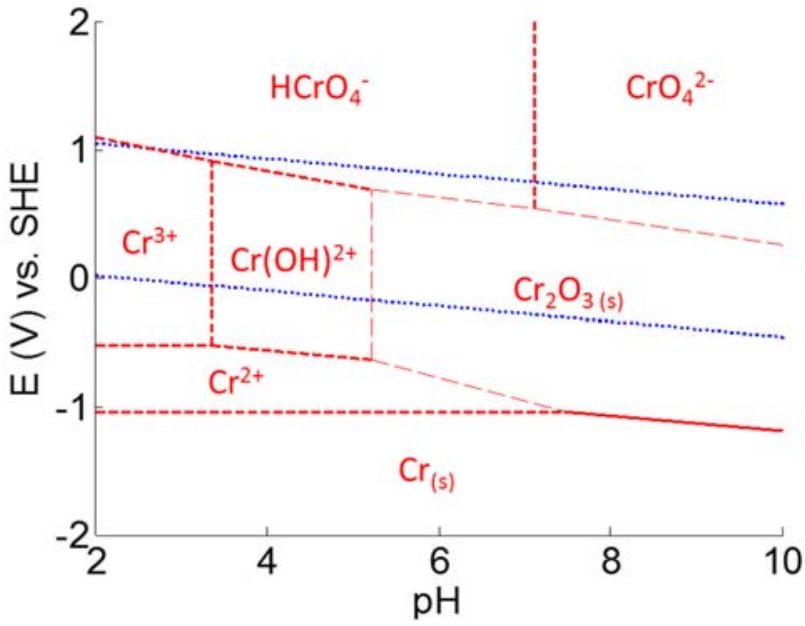

Figure 6: E-pH diagram for $\mathrm{Cr}-\mathrm{H}_{2} \mathrm{O}$ at $25^{\circ} \mathrm{C}$

Figure 5 and Figure 6 represent E-pH diagrams generated using the Matlab code developed using the aforementioned method and electrochemical equations for manganese-water and chromium-water systems, respectively. When the diagrams are overlaid on one another, the result is shown in Figure 3.

\section{EXPERIMENTAL DATA}

Similar to the overlapped shaded region in Figure 4, a restricted region can further be defined for a known temperature range of the device, containing information about both casing metal and inhibitors. An example is shown in Figure 7 from $25^{\circ} \mathrm{C}$ to $120^{\circ} \mathrm{C}$. Additional details for other temperature ranges and other inhibitor combinations can also be generated.

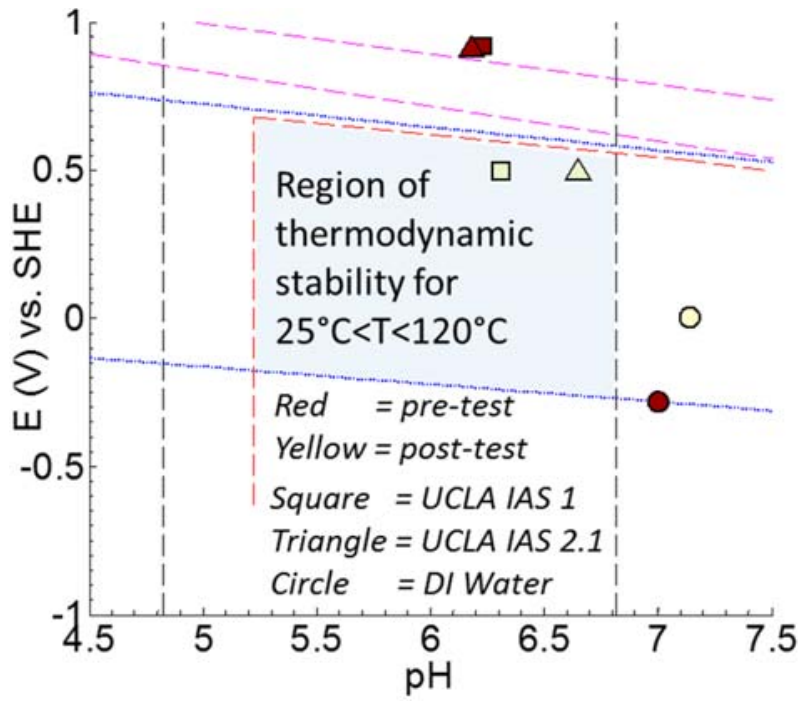

Figure 7: E-pH diagram for $\mathrm{Cr}-\mathrm{Mn}-\mathrm{H}_{2} \mathrm{O}$ system showing stable region for $25^{\circ} \mathrm{C}<T<120^{\circ} \mathrm{C}$

Within the shaded region of Figure 7, water, aluminum oxide, and chromium oxide are all stable. The safe region is defined by the most restrictive lines throughout the temperature range. For example, the right edge is a high temperature limit while the left edge is a low temperature limit. Additionally, chromate and permanganate reactions which do not produce NCG are more favorable to pure water/aluminum reactions which would produce hydrogen, providing further backup NCG protection. Measurements from Stubblebine and Catton [13] and Yao et al. 
[24] have also been added to Figure 7 . The temperature range $25^{\circ} \mathrm{C}$ to $120^{\circ} \mathrm{C}$ was selected based upon the temperature range experienced during the experiments this data was collected from. The shaded safe region represents the most restrictive lines that can be drawn for each equilibrium system over the temperature range.

Table 1: E and pH measurements from past aluminum heat pipe and

\begin{tabular}{|c|c|c|c|c|c|c|c|c|}
\hline \multicolumn{9}{|c|}{ thermosiphon experiments } \\
\hline Fluid & Paper Ref. & $\mathrm{pH}_{\mathrm{i}}$ & $\mathrm{pH}_{\mathrm{f}}$ & \begin{tabular}{|l|}
$E_{i}$ \\
$(m V)$ \\
\end{tabular} & \begin{tabular}{|l|}
$E_{f}$ \\
$(m V)$
\end{tabular} & \begin{tabular}{|l|}
$\mu \mathrm{mol}$ \\
$\mathrm{Mn} / \mathrm{cm}^{2}$
\end{tabular} & $\begin{array}{l}\mu \mathrm{mol} \\
\mathrm{Cr} / \mathrm{cm}^{2}\end{array}$ & \begin{tabular}{|l|} 
Data \\
Point \\
\end{tabular} \\
\hline UCLA IAS 2.1 & $\begin{array}{l}\text { Yao et al. } \\
{[24]}\end{array}$ & \begin{tabular}{|l|}
6.18 \\
$+/-0.04$ \\
\end{tabular} & \begin{tabular}{|l}
6.65 \\
$+/-0.04$ \\
\end{tabular} & $\begin{array}{r}910 \\
+/-7 \\
\end{array}$ & \begin{tabular}{|l|}
494 \\
$+/-4$ \\
\end{tabular} & .038 & 1.06 & triang \\
\hline UT Wrater & $\begin{array}{l}\text { Stubblebine } \\
\text { and Catton } \\
\text { [13] }\end{array}$ & $\begin{array}{l}7.00 \\
+/-0.04\end{array}$ & \begin{tabular}{|l}
7.14 \\
$+/-0.04$
\end{tabular} & $\begin{array}{l}-281 \\
+/-3\end{array}$ & $\left|\begin{array}{|}4 \\
+/-2\end{array}\right|$ & 0.00 & 0.00 & circle \\
\hline ICLA IAS 1 & $\begin{array}{l}\text { Stubblebine } \\
\text { and Catton } \\
\text { [13] }\end{array}$ & \begin{tabular}{|l}
6.23 \\
$+/-0.04$
\end{tabular} & \begin{tabular}{|l}
6.31 \\
$+/-0.04$
\end{tabular} & $\begin{array}{r}920 \\
+/-7\end{array}$ & $\begin{array}{l}497 \\
+/-4\end{array}$ & 0.214 & 5.93 & \\
\hline
\end{tabular}

Measurements of $\mathrm{E}$ and $\mathrm{pH}$ were taken both before testing and after testing. The $\mathrm{pH}$ measurements were done using an Omega probe and have an accuracy of $+/-0.02 \mathrm{pH}+2 \mathrm{~d}$ while the $\mathrm{E}$ measurements are $+/-0.5 \%+2 \mathrm{~d}$, giving accurate measures for each fluid. Summary of these data can be found in Table 1. The experiments from Stubblebine and Catton [13] are both from aluminum flat plate heat pipe experiments with rectangular grooves. The data from Yao et al. [24] is from an aluminum thermosiphon in vertical orientation with a quiescent ice bath condenser. Further details on exact experimental conditions can be found in the respective full texts.

In Figure 7, red points represent measurements taken before testing and yellow points are from measurements after testing taken from extracted fluid. The flat heat pipe data for de-ionized (DI) water (circle points) is well outside the boundaries of the safe region, as might be expected for pure water. Stubblebine and Catton [13] report the DI water test did fail and that there were no observable signs of NCG generation for the test with inhibitors. Yao et al. [24] also reported no observable signs of NCG generation in their experiment. It can be seen that both solutions using $\mathrm{Mn}$ and $\mathrm{Cr}$ inhibitors (triangle and square points) start with nearly identical point locations (they use nearly identical inhibitor concentrations) and their final measurements are both within the safe region defined in Figure 7. Considering that each inhibitor fluid test was conducted under entirely different heat transfer conditions yet yielded comparable post test chemical analysis results which matched prediction, the proposed method has been shown to be reliable for these cases.

The slightly different final locations for the two inhibitor fluids are a result of the very different geometries and fluid charges used. Comparing the chemical amounts per unit surface area in Table 1, the difference becomes clear. This underlines the importance of considering the amount of surface area exposed as well, including the larger surface areas introduced by the use of heat pipe wicks. The proximity of the post test points for both inhibitor experiments to the right boundary in Figure 7 suggests a slightly more acidic $\mathrm{pH}$ be used for future fluids if higher temperature tests are to be conducted and that further calculations are done to estimate the amount of consumed $\mathrm{Cr}$ inhibitors and determine if higher concentrations might be necessary for additional long term protection.

When using this method during a full study of optimal inhibitors and concentrations per unit device surface area, failed inhibitor experiments will fall outside the safe zone. The precise location provides information which can be used to inform new fluid designs either with different concentrations of the same inhibitors or different inhibitors altogether.

\section{CONCLUSIONS}

A new method for evaluating heat pipe casing and fluid compatibility has been introduced which can be used to help screen for appropriate inhibitors in aqueous solution. Using aluminum heat pipes with $\mathrm{Mn}$ and $\mathrm{Cr}$ based inhibitors as a case study, chemical equations were selected and used to generate E$\mathrm{pH}$ equilibrium diagrams showing the most thermodynamically stable forms of the constituents for a range of conditions.

Experimental data from both aluminum heat pipe and thermosiphon experiments were plotted on a figure for which the most restrictive equilibrium lines were drawn over the temperature range experienced by the tests. Points from pure DI water which failed experimentally were shown to be outside the established safe region. Data points from the fluids with inhibitors, one from a thermosiphon and one from a grooved heat pipe, were both found within the safe region.

Future work will use this thermodynamic approach to assess the impact of different inhibitor concentrations with respect to the internal surface area exposed. The utility of other oxidizing agents will be investigated by generating similar thermodynamic data and diagrams for those metal-water systems. The approach used is not limited in application to aluminum casings; other materials such as steels can be investigated as well by replacing the base metal aluminum with the desired material.

\section{ACKNOWLEDGMENT}

We would like to acknowledge the support for this work under the National Science Foundation (NSF) award number CBET-1336896. The views, opinions, and findings contained in this article are those of the author and should not be interpreted as representing the official views or policies, either expressed or implied, of the National Science Foundation.

\section{REFERENCES}

[1] Chi, S., 1976, "Heat pipe theory and practice," Washington, DC, Hemisphere Publishing Corp.; New York, McGraw-Hill Book Co., 1976. 256 p., 1.

[2] Reay, D. A., 1982, "The Perkins Tube - a noteworthy contribution to heat exchanger technology," Journal of Heat Recovery Systems, 2(2), pp. 173-187.

[3] Reay, D., and Kew, P. A., 2006, Heat pipes: Theory, design and applications, Butterworth Heinemann.

[4] Faghri, A., 1995, Heat pipe science and technology, Global Digital Press.

[5] Faghri, A., 2014, "Heat Pipes: Review, Opportunities, and Challenges," Frontiers in Heat Pipes (FHP), 5(1).

[6] Heuer, C. E., 1979, "The application of heat pipes on the Trans-Alaska pipeline," C. R. R. a. E. Laboratory, ed.Hanover, NH, USA, p. 33.

[7] Semenic, T., and Catton, I., 2009, "Experimental study of biporous wicks for high heat flux applications," International Journal of Heat and Mass Transfer, 52(21), pp. 5113-5121.

[8] Rassamakin, B. M., Gomelya, N. D., Khairnasov, N. D., and Rassamakina, N. V., 1997, "Choice of the effective inhibitors of corrosion and the results of the resources tests of steel and aluminum thermosyphon with water," Proc. Proceedings of the 10th International Heat Pipes Conference, pp. 90-93.

[9] Novotna, I., Nassler, J., and Zelko, M., 1988, "Compatibility of Steel-Water Heat Pipes," Proc. Proceeding of the Third International Heat Pipe Symposium, Tsukuba, Japan, pp. 89-95. 
[10] Novotna, I., Nassler, J., and Zelko, M., 1988, "Contribution to Compatibility of Steel-Water Heat Pipes," Proc. 3rd International Heat Pipe Symposium, pp. 319-327.

[11] Reilly, S., Amouzegar, L., Tao, H., and Catton, I., 2011, "Use of Inorganic Aqueous Solutions for Passivation of Heat Transfer Devices," Proc. 10th International Heat Pipe Symposium.

[12] Stubblebine, M., Reilly, S., Yao, Q., and Catton, I., 2013, "Use of an Inorganic Aqueous Solution to Prevent NonCondensable Gas Formation in Aluminum Heat Pipes," ASME Summer Heat Transfer ConferenceMinneapolis, MN.

[13] Stubblebine, M. J., and Catton, I., 2015, "Passivation and Performance of Inorganic Aqueous Solutions in a Grooved Aluminum Flat Heat Pipe," Journal of Heat Transfer, 137(5), pp. 052901-052901.

[14] Terdtoon, P., Charoensawan, P., and Chaitep, S., 2001, "Corrosion of tubes used in thermosyphon heat exchanger for waste heat recovery system: A case of internal surface," Heat Transfer Eng, 22(4), pp. 18-27.

[15] Revie, R. W., 2008, Corrosion and corrosion control, John Wiley \& Sons.

[16] Uhlig, H. H., and Revie, R. W., 2011, Uhlig's corrosion handbook, John Wiley \& Sons.

[17] Helgeson, H. C., and Kirkham, D. H., 1976, "Theoretical prediction of the thermodynamic properties of aqueous electrolytes at high pressures and temperatures. III. Equation of state for aqueous species at infinite dilution," American Journal of Science, 276(2), pp. 97-240.

[18] Oelkers, E. H., Helgeson, H. C., Shock, E. L., Sverjensky, D. A., Johnson, J. W., and Pokrovskii, V. A., 1995, "Summary of the Apparent Standard Partial Molal Gibbs Free-Energies of Formation of Aqueous Species, Minerals, and Gases at Pressures 1 to 5000 Bars and Temperatures 25 to 1000-Degrees-C," Journal of Physical and Chemical Reference Data, 24(4), pp. 1401-1560.

[19] Shock, E. L., and Helgeson, H. C., 1988, "Calculation of the thermodynamic and transport properties of aqueous species at high pressures and temperatures: Correlation algorithms for ionic species and equation of state predictions to $5 \mathrm{~kb}$ and $1000^{\circ} \mathrm{C}$," Geochimica et Cosmochimica Acta, 52(8), pp. 20092036.

[20] Tanger, J. C., and Helgeson, H. C., 1988, "Calculation of the Thermodynamic and Transport-Properties of Aqueous Species at High-Pressures and Temperatures - Revised Equations of State for the Standard Partial Molal Properties of Ions and Electrolytes," American Journal of Science, 288(1), pp. 19-98.

[21] Shock, E. L., Sassani, D. C., Willis, M., and Sverjensky, D. A., 1997, "Inorganic species in geologic fluids: Correlations among standard molal thermodynamic properties of aqueous ions and hydroxide complexes," Geochimica et Cosmochimica Acta, 61(5), pp. 907-950.

[22] Ghali, E., 2010, Corrosion resistance of aluminum and magnesium alloys: understanding, performance, and testing, John Wiley \& Sons.

[23] Yao, Q., Stubblebine, M., Reilly, S., Amouzegar, L., and Catton, I., 2013, "Using an Inorganic Aqueous Solution (IAS) in Copper and Aluminum Phase Change Heat Transfer Devices," International Mechanical Engineering Congress and Exposition, ASME, San Diego, CA.

[24] Yao, Q., Stubblebine, M. J., and Catton, I., 2015, "Importance of Continuous Liquid Back Flow when using an Inorganic Aqueous Solution (IAS) in Aluminium Heat Transfer Devices," ASME-ATI-UIT Conference on Thermal Energy
Systems: Production, Storage, Utilization and the EnvironmentNapoli, Italy.

\section{NOMENCLATURE}

\begin{tabular}{|c|c|c|}
\hline Symbol & Quantity & SI Unit \\
\hline$A, B, C, D$ & $\begin{array}{l}\text { Species placeholders in } \\
\text { equilibrium } \\
\text { equation }\end{array}$ & dimensionless \\
\hline$a, b, c, d$ & $\begin{array}{l}\text { Species coefficients from } \\
\text { reaction equation }\end{array}$ & dimensionless \\
\hline$a_{3}$ & Species specific constant & $\mathrm{J} \mathrm{K} / \mathrm{mol} \mathrm{Pa}$ \\
\hline$a_{4}$ & Species specific constant & $\mathrm{J} \mathrm{K} / \mathrm{mol}$ \\
\hline$c_{1}$ & Species specific constant & $\mathrm{J} / \mathrm{mol} \mathrm{K}$ \\
\hline$c_{2}$ & Species specific constant & $\mathrm{J} \mathrm{K} / \mathrm{mol}$ \\
\hline$C_{p}$ & $\begin{array}{l}\text { Molar specific heat, } \\
\text { constant pressure }\end{array}$ & $\mathrm{J} / \mathrm{mol} \mathrm{K}$ \\
\hline E & Reduction potential & Volts \\
\hline$F$ & Faraday's constant & Coulomb $/ \mathrm{mol}$ \\
\hline$G$ & Molar Gibbs energy & $\mathrm{J} / \mathrm{mol}$ \\
\hline$H$ & Molar enthalpy & $\mathrm{J} / \mathrm{mol}$ \\
\hline$K$ & Equilibrium constant & dimensionless \\
\hline$n$ & $\begin{array}{l}\text { Number of electrons } \\
\text { transferred }\end{array}$ & dimensionless \\
\hline$P$ & Pressure & $\mathrm{Pa}$ \\
\hline$p H$ & Potential of hydrogen & dimensionless \\
\hline$Q$ & Reaction quotient & dimensionless \\
\hline$R$ & Universal gas constant & $\mathrm{J} / \mathrm{mol} \mathrm{K}$ \\
\hline$S$ & Molar entropy & $\mathrm{J} / \mathrm{mol} \mathrm{K}$ \\
\hline SHE & $\begin{array}{l}\text { Standard hydrogen } \\
\text { reference electrode }\end{array}$ & \\
\hline$T$ & Temperature & $\mathrm{K}$ \\
\hline$U$ & Molar internal energy & $\mathrm{J} / \mathrm{mol}$ \\
\hline$V$ & Volume & $\mathrm{m}^{3}$ \\
\hline$X$ & Born function & $1 / \mathrm{K}^{2}$ \\
\hline$Y$ & Born function & $1 / \mathrm{K}$ \\
\hline$\Delta$ & Change in quantity & \\
\hline$\varepsilon$ & Dielectric constant, water & dimensionless \\
\hline$\omega$ & $\begin{array}{l}\text { Conventional Born } \\
\text { coefficient for ionic species }\end{array}$ & $\mathrm{J} / \mathrm{mol}$ \\
\hline$\theta$ & Global temperature constant & $228 \mathrm{~K}$ \\
\hline$\psi$ & Global pressure constant & $2.6 \times 10^{7} \mathrm{~Pa}$ \\
\hline
\end{tabular}

Subscript Quantity

$\begin{array}{ll}(a q) & \text { Aqueous phase } \\ f & \text { Formation } \\ (g) & \text { Gaseous phase } \\ (l) & \text { Liquid phase } \\ P & \text { Constant pressure } \\ r & \text { Reaction } \\ r e f & \text { Reference quantity } \\ (s) & \text { Solid phase } \\ T & \text { Constant temperature }\end{array}$

Superscript Quantity 